\title{
NOBILITADOS ENTRE CRISTÃOS-NOVOS E FAMILIARES DO SANTO OFÍCIO: O EXEMPLO DAS CASAS DA FAMÍLIA REAL
}

\author{
Maria Paula Marçal Lourenço \\ (Faculdade de Letras da Universidade de Lisboa/Centro de História da Universidade \\ de Lisboa/Académica de Número da Academia Portuguesa da História)
}

\section{RESUMO}

A partir dos fundos inquisitoriais portugueses, mas seguindo metodologias diversificadas das praticadas nos estudos mais recentes sobre a Inquisição, é objectivo deste texto dar a conhecer de que formas as elites jurídicas das duas principais Casas da Família Real, a Casa das Rainhas (1640-1754) e a Casa do Infantado (1654-1706) progrediram social e politicamente, alcançando honras, privilégios, «nobreza» e prestígio, não obstante, alguns dos seus membros nem sempre conseguirem provar a sua total «limpeza de sangue» ou por mácula de «mecânico» ou de cristão-novo.

PALAVRAS-CHAVE: Cristãos-novos, «limpeza de sangue», Casa das Rainhas, Casa do Infantado, elites jurídicas das Casas da Família Real.

\section{NOBILITY IN NEW CHRISTIANS AND FAMILY OF THE HOLY OFFICE: THE EXAMPLE OF THE HOUSES OF THE ROYAL FAMILY}

\begin{abstract}
The purpose of this text is to provide information on the legal elites of the two main Houses of the Royal Family, Casa das Rainhas (1640-1754) and Casa do Infantado (1654-1706), based on Portuguese inquisitorial sources, but following different methodologies from those practiced in the most recent studies on the Inquisition. We will analyze how they progressed socially and politically, achieving honors, privileges, «nobility» and prestige, although some of its members are not always able to prove their total «blood cleansing» blemished by «Mechanical» or Christian-new.
\end{abstract}

KEYWORDS: Christian-new, «blood cleansing», Casa das Rainhas, Casa do Infantado, legal elites of the Houses of the Royal Family. 
Partindo do estudo dos percursos sociais e do cursus honorum de alguns dos mais destacados juristas ao serviço das Casas da Família Real e, em concreto, da Casa das Rainhas e da Casa do Infantado, é nosso propósito, nesta comunicação, relevar os principais critérios de recrutamento dessas elites que ocuparam os cargos preeminentes da magistratura de dois dos Tribunais Superiores da Coroa entre os séculos XVII e XVIII.

De acordo com a doutrina política da época esses lugares conferiam nobreza, honra e prestígio. Mas, nem por isso, eram menos disputadas as provas irrefutáveis de «limpeza de sangue» que se sucediam e multiplicavam, já que para o candidato que seguia a carreira de jurista eram vários os momentos em que se confrontava com inquirições e averiguações genealógicas.

Neste sentido, se é verdade que para alguns a suspeita de mácula de «raça de cristão-novo, mouro, ou mulato» permaneceu ao longo das suas vidas como estigma e infâmia dificilmente «expurgável» da memória colectiva, para muitos outros a «honra» conquistada através de morosas e dispendiosas inquirições de genere e do prestígio garantido pelos serviços à Coroa, perpetuou os poderes de notáveis juristas que, apesar da longínqua fama de «cristã-novice», alcançaram notáveis lugares nas Casas da Família Real em tempos de Inquisição ${ }^{1}$.

Origem social, formação letrada, cursus honorum e carreiras nas estruturas da administração da Coroa, da Casa das Rainhas e do Infantado constituirão alguns dos tópicos em análise, que se traduzirão, na prática, pela caracterização dos requisitos e formas de provimento e de progressão em magistraturas específicas: a das Rainhas e a do Infante como donatários da Coroa. Poderosas «linhagens» de juristas que com a sua honra, prestígio, influência cortesã e clientelar, souberam progressivamente conquistar lugares-chave ao serviço da Monarquia Absoluta.

Ao contrário do que já fizemos em trabalhos anteriores ${ }^{2}$, não nos interessa tanto, neste texto, os trâmites da progressão académica, embora ela esteja implícita nos critérios de escolha das elites jurídicas na época em estudo, entre a segunda metade do século XVII até meados do século XVIII, mas, sobretudo, destacar exemplos de servidores incólumes de «fama» ou «rumor» de sangue menos puro,

\footnotetext{
${ }^{1}$ A propósito da «obsessão» com a limpeza de sangue e honra-fama na escolha dos membros das estruturas da administração central e para o exemplo da monarquia espanhola vide, Janine Fayard, Los miembros del Consejo de Castilla (1621-1746), (Madrid: Siglo XXI, 1979), 201-206. Para o caaso português vejam-se, entre outros, Fernanda Olival: "Juristas e Mercadores à Conquista das Honras: Quatro processos de nobilitação Quinhentistas, separata”, Revista de História Económica e Social, n ${ }^{\circ} 4$, $\left(2^{\mathrm{a}}\right.$ série/ $2^{\circ}$ semestre de 2002), 7-53.

${ }^{2}$ Maria Paula Lourenço, A Casa e o Estado Infantado (1654-1706). Formas e práticas administrativas de um Património Administrativo, (JNICT, Centro de História da Universidade de Lisboa, 1995). Maria Paula Marçal Lourenço, Casa, Corte e Património das Rainhas de Portugal (1640-1754). Poderes, Instituições e Relações Sociais, (Lisboa, dissertação de doutoramento em História Moderna apresentada à Faculdade de Letras da Universidade de Lisboa, 1999), 4 vols. (no prelo).
} 
com alguns outros que, apesar das diligências para se libertarem dessa infâmia, nunca o conseguiram fazer.

O conjunto absolutamente excepcional de privilégios de que dispunham, a Casa de Bragança, a Casa das Rainhas e a Casa do Infantado, como donatários de $1^{\text {a }}$ Ordem, dotavam estas três Casas da Família Real de estruturas similares às da Coroa ${ }^{3}$. Aliás, já não é hoje possível de acordo com a historiografia mais recente, falar apenas da Casa Real ou corte, mas sim das diferentes Casas, incluindo a de Bragança, a dos príncipes, princesas, infantas e infantes, já que estas constituíam realidades policêntricas, em que a Casa do Rei é uma entre diversas outras ${ }^{4}$.

Em rigor, a partir de 1642, tal como a Casa Real, a Casa das Rainhas possuía chancelaria própria e um Conselho da Fazenda das consortes régias. $\mathrm{Na}$ circunstância do «Regimento do Conselho da Fazenda e Estado da Rainha Nossa Senhora» criado por D. Luísa de Gusmão, em 11 de Outubro de 1656, este definia o estatuto, privilégios e funcionamento do órgão central de administração da Casa, verdadeiro tribunal superior, que adoptava o estilo e a forma de despacho do Desembargo do Paço e do Conselho da Fazenda ${ }^{5}$. O que significa que, desde logo, a rainha dispunha de largos poderes jurisdicionais em tudo idênticos aos dos principais órgãos da justiça e da fazenda régia ${ }^{6}$.

Por sua vez, a Casa do Infantado possuía, a partir de 1654, chancelaria própria e uma Junta da Fazenda da Casa e Estado, semelhante em termos institucionais aos demais tribunais superiores ${ }^{7}$. Aliás, urge a realização de um trabalho de idêntica natureza para a Casa de Bragança, a partir de 1640, mas estamos em crer que seguia muito de perto os trâmites legais e administrativos dos até aqui considerados ${ }^{8}$.

A economia de tempo impõe que não sejam aqui definidas as atribuições dos secretários e chanceleres-mores das rainhas e dos infantes, muito embora constituíssem cargos de elevada honorabilidade.

${ }^{3}$ José Manuel Louzada Subtil, O Desembargo do Paço (1750-1833), (Lisboa: Universidade Autónoma de Lisboa, 1996).

${ }^{4}$ Pedro Cardim, "A Casa Real e os órgãos centrais de governo no Portugal na segunda metade de Seiscentos", Tempo, $\mathrm{n}^{\circ}$ 17, $\mathrm{n}^{\circ}$ 13; Política e Administração no Mundo Luso-brasileiro, (Rio de Janeiro: Universidade Federal Fluminense, 2002), 13-57.

${ }^{5}$ Maria Paula M. Lourenço, "O Regimento do Conselho da Fazenda e Estado de D. Luísa de Gusmão (1656): breve estudo das instituições da Casa das Rainhas a partir da $2^{a}$ metade do século XVII", Jornada de Estudo, Rainhas consortes e suas Casas da Idade Média à Idade Moderna, Lisboa, Faculdade de Letras da Universidade de Lisboa/Centro de História, (16 de Março de 2016), ( no prelo).

${ }^{6} \mathrm{AN} / \mathrm{TT}$, Casa das Rainhas, Copia do Regimento do Conselho da Fazenda e Estado da Raynha Nossa, $\mathrm{n}^{\circ}$ 46, liv. 12.

7 Lourenço: "O Regimento do Conselho".

${ }^{8}$ Mafalda Soares da Cunha, A Casa de Bragança 1560-1640. Práticas senhoriais e redes clientelares, (Lisboa: Estampa, 2000). 
Do ponto de vista da origem social dos secretários e chanceleres-mores das consortes régias, podemos considerar que, na sua maioria, se recrutaram no seio de famílias nobilitadas ao serviço da Casa Real. O mesmo sucedia com os ministros da Chancelaria e Secretaria da Junta da Casa do Infantado.

Vejamos alguns exemplos ilustrativos para ambas as instituições. Para a Casa das Rainhas, não só André Franco adquire o hábito da Ordem de Santiago pelos serviços militares de seu pai ${ }^{9}$, como Martim Monteiro Paim era filho de Pedro Fernandes Monteiro «tão benemérito ao serviço desta Coroa» ${ }^{10}$. Aliás, o mesmo sucedia com a Casa do Infantado, como já tivemos oportunidade de estudar. Por outro lado, António de Basto Pereira descendia do doutor Luís Gomes de Basto que, para além de pertencer ao Conselho do Rei e ao Desembargo do Paço, era fidalgo da Casa Real ${ }^{11}$, enquanto os avós de José Vaz de Carvalho viviam «à lei da nobreza», sendo o pai doutor e conservador da Universidade de Coimbra e familiar do Santo Ofício $^{12}$.

No caso paradigmático dos Rego de Andrade., Belchior do Rego de Andrade, primeiro desta família a servir a Casa das Rainhas, descendia dos servidores dos Bragança, já que seu pai havia sido moço de guarda-roupa de D. Teodósio II, e sua mãe filha de outro guarda-roupa do duque ${ }^{13}$. Por outro lado, o segundo Belchior do Rego de Andrade era filho do desembargador Inácio do Rego e Andrade, conselheiro da Casa, que, por sua vez, era sobrinho do primeiro, homónimo do último ${ }^{14}$.

À excepção de um ou outro caso, quase todos eram naturais de Lisboa e a proveniência dos seus progenitores era, de igual forma, lisboeta. Desde logo, parece indiciar o preferencial recrutamento deste tipo de cargos da Casa entre as elites letradas da Coroa, em especial, entre o corpo de juristas que serviam a Casa de Bragança e, de um modo geral, a Casa Real. Boa parte destes homens, como podemos facilmente constatar, pertenciam a sucessivas gerações de juristas como os Rego de Andrade, os Monteiro Paim, os Almeida de Carvalho, entre outros. Solidariedades geográficas, familiares, profissionais cruzavam-se com frequência na promoção de parentes das mesmas casas senhoriais.

Os dois chanceleres que serviram a Casa do Infantado, entre 1654 e 1706, João Rodriguez Fontoura e António Rodriguez Lemos eram altos magistrados que provinham de tribunais superiores, tais como a Junta da Casa de Bragança e, para além disso, no primeiro caso, do Desembargo da Casa da Suplicação, sendo o

\footnotetext{
${ }^{9} \mathrm{AN} / \mathrm{TT}$, Habilitações da Ordem de Santiago, letra A, maço 7, no 14.

${ }^{10} \mathrm{BNF}$, Manuscrits Portugais, no 32, fl. 157.

11 AN/TT, Desembargo do Paço. Leitura de Bacharéis, letra A, maço no $7, \mathrm{n}^{\circ} 14$.

12 AN/TT, Desembargo do Paço. Leitura dos Bacharéis, letra J, maço n $2, \mathrm{n}^{\circ} 23$.

13 Diego Barbosa de Machado, "Belchior do Rego de Andrade", Bibliotheca Lusitana, Historica, Chronologica (....), (Lisboa: 1930, tomo I, $2^{a}$ ed., 1930), 44.

${ }^{14} \mathrm{BNP}$, Livro de assentos e registos da leitura de bacharéis no Desembargo do Paço a partir de 20 de Outubro de 1660 até 8 de Agosto de 1736, Reservados, cód. 10856.
} 
segundo desembargador dos Agravos e Feitos da Coroa e Fazenda ${ }^{15}$. Apesar de não haver registo da habilitação do Santo Ofício para nenhum destes juristas, certo é que as «letras e confiança» neles depositada mostram bem o seu estatuto exemplar, sem mancha de sangue cristão-novo, e, por isso mesmo, granjeando de grande reputação junto da Casa Real, tendo ambos ocupado lugares, em período anterior ou em simultâneo, de desembargadores da Casa de Bragança ${ }^{16}$.

Contudo, se descermos na escala hierárquica, o escrivão da Chancelaria da Casa do Infantado, Manuel Palha Leitão, não beneficiou da mesma «imaculada» condição. Não obstante, ter sido escrivão da câmara dos infantes D. Afonso e D. Pedro, escrivão da fazenda da Casa do Infantado, não lhe foi concedida a habilitação para familiar de Santo Ofício, por decisão tomada em 10 de Janeiro de 1663, em virtude de «constar» das inquirições genealógicas que a avó materna, Catarina Milão, era cristã-nova ${ }^{17}$. Neste caso, e não conhecemos mais nenhum processo de habilitação posterior, nem os serviços à coroa serviram de pretexto fiável para conceder o tão desejado estatuto de familiar do Santo Ofício.

Como é sobejamente sabido, para quem seguia a carreira de jurista eram, aliás, múltiplas as etapas em que eram confrontados com inquirições e averiguações genealógicas. Desde o registo de ingresso nas Faculdades de Leis e/ou Cânones, em geral na Universidade de Coimbra, nos colégios de S. Pedro e S. Paulo, à leitura de bacharéis e respectivas inquirições de genere efectuadas perante a mesa do Desembargo do Paço, ao exame para advogado da Casa da Suplicação, diversos eram os trâmites processuais que, sobretudo, a partir da primeira metade do século XVII, tornaram mais difícil o acesso às carreiras jurídicas. Através deles, e por eles, legitimava-se o sangue nobilitado, que expurgado de «impureza» de certos antepassados, tornava-se «honrado» pelo desempenho de cargos civis.

Com efeito, em várias das habilitações de genere para as «leituras de bacharéis» dos futuros secretários da Casa das Rainhas, regista-se «a limpeza de toda a raça de cristão-novo, mouro ou mulato, sem que descendam de oficial mecânico». Por vezes as aparências iludiam. E nem sempre as averiguações definitivas correspondiam à realidade dos factos.

É assim que, Francisco Nunes Cardeal, filho de sapateiro e curtidor, mas neto de «lavradores» que viviam por sua fazenda, conseguiu, não obstante as inquirições genealógicas, ocupar alguns dos principais cargos da administração central, vindo a ser um dos secretários da rainha D. Maria Ana de Áustria ${ }^{18}$. Mas a prova máxima constituía a posse de um hábito de uma Ordem Militar, em especial a de Cristo.

15 AN/TT, Chancelaria da Casa do Infante D. Pedro, livro 1,fls. 1v. e 118.

16 Maria Paula Marçal Lourenço, A Casa e o Estado do Infantado 1654-1706. Formas e Práticas Administrativas de um Património Senhorial, (Lisboa: JNICT/Centro de História da Universidade de Lisboa, 1995), 78.

17 AN/TT, Habilitações do Santo Ofício, Manuel, maço 29, diligência no 604.

18 AN/TT, Habilitações do Santo Ofício, Francisco, maço 15, diligência no 457. 
Como sublinhámos, André Franco recebera o hábito da Ordem de Santiago antes de iniciar a sua carreira de jurista e os Rego de Andrade tudo farão para «limpar» a sua fama de cristãos-novos.

De facto, a habilitação de Belchior do Rego de Andrade -sexto secretário e chanceler-mor da Casa das Rainhas, após 1640- ilustra com acuidade, as dificuldades, mesmo para uma família de notáveis juristas como esta, em aceder a um hábito da Ordem de Cristo. A suspeita de «cristã-novice» recaía sobre o seu avô paterno, António de Andrade, já que a mãe deste, D. Inocência Cacela era filha de Belchior do Rego de Andrade «que padeceo a dita fama que era parente de huns cristãos novos a que chamavão Mijatos» ${ }^{19}$. Apesar deste último ter sido admitido como irmão da Misericórdia de Vila Viçosa o «que se estranhara muito», a mesma sorte não tivera o primeiro Belchior do Rego de Andrade, pois que os testemunhos difamatórios de criados da Casa de Bragança impediram o solicitante de se tornar mesário ${ }^{20}$. Também por idênticos motivos, o duque $\mathrm{D}$. Teodósio não o teria provido em igreja curada. $\mathrm{O}$ parecer final da Mesa da Consciência e Ordens concluía que «por tudo se mostra não estar o justificante capas de entrar na Ordem, e se julgou por inhabilitado» ${ }^{21}$.

A verdade é que na habilitação de genere para familiar do Santo Ofício - e decorridos mais de trinta anos em que serviu, exemplarmente, a monarquia - o $6^{\circ}$ Secretário da Casa das Rainhas é referido como sendo cavaleiro da Ordem de Cristo e, não obstante, as dúvidas que continuavam a pairar, ainda em 1732, sobre a limpeza de sangue dos avós do $1^{\circ}$ Belchior, é evocada a irrefutável honra de seu irmão, o doutor António de Andrade Rego, lente de Cânones na Universidade de Coimbra, e nessa data, colegial no Colégio Real «onde se costumão fazer com muita exacção as inquirições» $»^{22}$. O valor e a irrefutabilidade de algumas das averiguações de genere feitas por certas instituições dispensavam outras. Ultrapassadas umas, conquistavam-se outras.

Para além disso, o justificante progrediu com largo sucesso na carreira jurídica, ocupando, como veremos, os principais lugares da Administração Central. Quando, em 17 de Abril de 1738, o Santo Ofício autorizava a impressão do Elogio Fúnebre de Belchior Rego de Andrade feito pelo Marquez de Valença já os estigmas de sangue cristão-novo estavam de há muito esquecidos ${ }^{23}$. De sublinhar, que o elogio fúnebre, que fixava a imagem modelar do magistrado e da sua linhagem, que visava preservar os actos e a memória de homens notáveis pela honra, pelo sangue ou pelo serviço exemplar à monarquia, foi proferido, exactamente, por um membro da nobreza titulada o Marquês de Valença. A «honra» conquistada pelas sucessivas e quase

${ }^{19}$ AN/TT, Habilitações da Ordem de Cristo, letra B, Maço 12, doc. 58.

${ }^{20}$ Ibídem.

${ }^{21}$ Ibídem.

${ }^{22}$ AN/TT, Habilitações do Santo Ofício, Belchior, maço 3, diligência n ${ }^{\circ} 45$.

${ }^{23}$ Elogio fúnebre de Belchior do Rego de Andrade feito pelo Marquez de Valença, Lisboa Occidental, na Officina de Miguel Rodrigues, impressor do Eminent. Senhor Cardeal Patriarca, 1738, com todas as licenças necessárias. 
sempre dispendiosas inquirições de genere e o prestígio garantido pelos serviços à Coroa- do próprio ou de familiares- apagavam os rumores e a «a fama» de «cristãonovo» ou de «mecânico» ${ }^{24}$.

Por outro lado, pelo menos, quatro dos dez secretários da Casa da Rainha foram familiares do Santo Ofício. Se é um facto, que nem todos poderiam alcançar um hábito numa Ordem Militar, ou a beca de um Colégio Maior, o acesso ao lugar de familiar, «agente benévolo», que servia voluntária e gratuitamente a instituição, era frequente. Assim parece ter sucedido com Francisco Nunes Cardeal, com Manuel de Almeida de Carvalho, ele próprio filho de familiar e futuro deputado do Santo Ofício $^{25}$. Nos casos do segundo Belchior do Rego de Andrade e de José Vaz de Carvalho, após alcançarem o hábito de Cristo, conquistaram um lugar de familiar do Santo Ofício ${ }^{26}$. Claro, que o notável António Cavide, Fidalgo da Casa Real, Secretário dos negócios estrangeiros da Casa e Estado e membro do Conselho da Fazenda e Secretário régio não necessitava da urgente «nobilitação» conferida pelo estatuto de familiar do Santo Ofício. Muito menos António de Sousa Tavares, Secretário da Casa do Infantado, da Casa de Bragança e Conselheiro do rei.

Em quaisquer das circunstâncias, facilitava se antepassados haviam já sido cavaleiros de uma Ordem Militar, familiares do Santo Ofício, desembargadores, doutores ou lentes universitários e, por isso, mesmo, as provas de «limpeza de sangue» repetiam-se, acumulavam-se e consolidavam a «honra» e a «fama» do solicitante.

Nobreza adquirida pelos serviços de pais e avós, ou dos próprios, fidalgos da Casa Real, cavaleiros das Ordens Militares, familiares do Santo Ofício mas, acima de tudo, nobreza de «letras», não raro com antepassados de humilde condição cuja formação letrada permitiu não só o acesso às magistraturas, como inclusive à nobilitação. De facto, vários dos pais dos secretários e chanceleres-mores das Casas desempenharam cargos de advogados e de desembargadores, sendo, pelo menos, bacharéis.

Com efeito, como tem vindo a ser provado pelos estudos de José Taveira da Fonseca e José Subtil, era rara a presença da primeira nobreza de corte na magistratura dos diversos tribunais da Coroa, à excepção da sua presidência. $\mathrm{Na}$ realidade, e a partir de uma lista elaborada por este último autor, dos cerca de dois

\footnotetext{
${ }^{24}$ Sobre as despesas com as inquirições de genere, veja-se Fernanda Olival, As Ordens Militares e o Estado Moderno. Honra, Mercê e Venalidade (1641-1789), (Lisboa: Estar Editora, 2001).

${ }_{25}$ AN/TT, Habilitações do Santo Ofício, Francisco, maço 15, diligência $n^{\circ} 457$. AN/TT, Leitura de bacharéis, Manuel, letra M, maço 25, no 13.

${ }^{26}$ AN/TT, Habilitação do Santo Ofício, Belchior, maço 3, diligência no 45; AN/TT, Habilitações do Santo Ofício, José, maço 6, diligência nº 120.
} 
milhares de desembargadores de todos os tribunais, entre 1640 e 1826, seriam, pelo menos, de $1 \%$ os que provinham da alta aristocracia ${ }^{27}$.

A maior parte dos secretários da Casa eram bacharéis em Direito Canónico ou em Leis pela Universidade de Coimbra, sendo, pelo menos, três licenciados, tendo um, Manuel Gomes de Carvalho, adquirido o grau de doutor. Este último, era ainda colegial do colégio de S.Pedro ${ }^{28}$. Estamos, portanto, perante um corpo de académicos cujo prestígio esteve, antes de mais, associado à sua formação universitária em Coimbra e que pertenceu à elite letrada da sua época.

Vejamos, em seguida, e para uma correcta definição do perfil socioprofissional destes oficiais, as etapas na progressão na carreira de jurista, em primeiro lugar, nas instituições centrais da Coroa e, num segundo momento, nos cargos administrativos da Casa das Rainhas.

Para aceder à carreira de magistrado na administração da Coroa era indispensável realizar o exame de «leitura de bacharéis» efectuado pelo Desembargo do Paço e que constituía, como tem sido diversas vezes realçado, um dispositivo burocrático de controlo e de disciplina da magistratura territorial. Em princípio, todos os secretários das rainhas, tal como os dos infantes, deveriam ter feito a respectiva leitura de bacharel.

Como tivemos oportunidade de concluir noutro estudo, praticamente para todos foi possível encontrar a habilitação de genere para servir nos lugares de letras ${ }^{29}$. Contudo, atendendo a que os desembargadores e filhos de desembargadores, os lentes das faculdades de Leis e os ministros do Santo Ofício, estavam isentos desse exame é provável que alguns desses magistrados se tenham exímido dessa prova ${ }^{30}$. No caso de Manuel de Almeida de Carvalho, este foi dispensado das habituais «inquirições» por ocupar já um lugar de desembargador da Casa da Suplicação ${ }^{31}$.

Por outro lado, apenas se podiam candidatar à «leitura» os proponentes com a qualificação mínima de «Bom», informação que era previamente remetida pela Universidade de Coimbra ao Desembargo do Paço, e que nos permite, uma vez mais, concluir pela boa ou excelente formação deste corpo de académicos. Excluídos

${ }^{27}$ Fernando Taveira da Fonseca, A Universidade de Coimbra (1700-1711), Estudo Económico e Social, (Coimbra: 1995); veja-se o trabalho de José Subtil, "Os desembargadores em Portugal (1640-1826)". OPTIMA PARS; Relatório policopiado citado por Nuno Gonçalo Monteiro, Elites e Poder Entre o Antigo Regime e o Liberalismo, (Lisboa: Imprensa de Ciências Sociais, 2003), 126.

${ }_{28}$ AN/TT, Habilitações do Santo Ofício, Letra M, maço 25, nº 13.

${ }^{29}$ Lourenço, Casa.

${ }^{30}$ Contudo, as leituras de bacharéis nem sempre se verificaram, pois os desembargadores, os lentes das Faculdades de Leis e Cânones e os ministros do Santo Ofício estavam isentos desse exame. Confrontar, sobre esta matéria, A. M. Hespanha, As Vésperas do Leviathan. Instituições e Poder Político. Portugal- Século XVIII, (Lisboa: edição do autor, 1986) 1 vol., 418-420.

31 AN/TT, Habilitações do Santo Ofício, letra M, maço 25, nº 13. 
estavam, no plano teórico, os letrados «medíocres», os que apresentavam mácula de ocupações «mecânicas» ou os que tivessem fama de cristãos-novos ${ }^{32}$.

Porém, nem sempre terá sido assim. De facto, e apenas para citar um exemplo, sob os Rego de Andrade pairava o estigma de sangue cristão-novo e, nem, por isso, deixaram os dois Belchiores de transitar nas respectivas leituras de «bacharéis». Por fim, para serem aprovados no exame de leitura teriam de obter a classificação de «Bem» ou «Muito Bem» por todos, ou pela maioria. Existiram, contudo, excepções à regra. O segundo Belchior do Rego de Andrade foi aprovado na sua leitura com apenas 4 votos «bem» e três que «leu», o que sucedeu, aliás, com outros magistrados da Casa das Rainhas ${ }^{33}$.

Praticamente, no seu conjunto, todos os secretários e chanceleres-mores das rainhas foram desembargadores o que os caracteriza como um corpo específico, quer pelas formas de acesso e promoção na carreira, quer pelos seus privilégios, no conjunto da magistratura letrada. Como tem sido por diversas vezes realçado, ser desembargador significava pertencer à elite dos oficiais régios, apenas superada em privilégios pelos secretários de Estado. Assim sendo, os desembargadores, magistrados de nomeação definitiva, desempenhavam os principais cargos de administração central, de justiça e da «graça», isto é, asseguravam a direcção do governo da nação, exercendo uma elevada fatia do poder político.

De facto, a maioria dos secretários das rainhas não seguiu o moroso circuito que distava da magistratura territorial até ao desempenho de cargos nos Tribunais Superiores da Coroa. Para quase todos, as duas vias de chegada a desembargadores parecem, ter sido, em primeiro lugar, através do direito consuetudinário, que permitia a indigitação para desembargador de um filho, neto ou sobrinho paterno, atendendo aos serviços dos seus parentes e, em segundo lugar, pela faculdade que possuíam os doutores e lentes da Universidade de Coimbra de acederem de imediato, caso desejassem, ao lugar de desembargador ${ }^{34}$. Na primeira circunstância estiveram, por certo, Martim Monteiro Paim, António de Basto Pereira, o segundo Belchior do Rego de Andrade e Manuel Almeida de Carvalho; no segundo caso, deve ter- se encontrado Manuel Gomes de Carvalho.

Ao observar as listas dos secretários e chanceleres-mores das rainhas, constatamos que foram múltiplos os cargos desemmpanhados por estes magistradoas, tais como os de juiz do contrato do sal, juiz dos feitos da cidade de Lisboa, juiz da alfândega do Tabaco, ouvidor da alfândega da Corte, corregedor do cível da Corte, juiz geral da Corte das Ordens e deputado da Mesa da Consciência e Ordens, procurador da fazenda dos Três Estados, procurador da fazenda real do Conselho

\footnotetext{
32 Subtil, O Desembargo, 298-304.

${ }^{33} \mathrm{BNP}$, Livro de assentos e registos de leitura (...), Reservados, cód. 10856, fl. $130 \mathrm{v}$.

${ }^{34}$ Subtil, O Desembargo, 324-332.
} 
Ultramarino e conselheiros do rei $^{35}$. O mesmo sucedeu com os ministros da Junta da Justiça e Fazenda da Casa do Infantado, onde vamos, aliás, encontrar os famosos Rego de Andrade como conselheiros do infante ${ }^{36}$.

Em suma, foi nos órgãos e tribunais régios que estes magistrados fizeram a sua carreira, com uma maior concentração de nomeações para os três principais da Coroa: a Relação do Porto, a Casa da Suplicação e o Desembargo do Paço. Note-se, por outro lado, que quatro dos juristas pertencentes à Casa das Rainhas chegaram a desembargadores do Paço, três antes de serem providos como secretários das rainhas - o segundo Belchior do Rego de Andrade, Manuel de Almeida de Carvalho e Manuel Gomes de Carvalho - e um depois - o primeiro Belchior do Rego de Andrade $^{37}$; e que um, António Basto Pereira, havia sido já Chanceler da Casa da Suplicação e secretário da Inconfidência, antes de ocupar o cargo de secretário da rainha D. Maria Ana de Áustria ${ }^{38}$.

Resumindo, tratavam-se de homens com larga experiência políticoadministrativa e, como tal, gente da estrita confiança da Coroa e da Família Real. Registe-se, ainda, que os secretários desempenharam esses cargos numa idade «madura», com a excepção lapidar do primeiro Belchior do Rego de Andrade que foi nomeado, sucessivamente, para essa função, por D. Luísa de Gusmão e pelas rainhas D. Maria Francisca Isabel de Sabóia e D. Maria Sofia de Neuburgo ${ }^{39}$.

Sublinhe-se, por outro lado, que a própria Casa das Rainhas ofereceu oportunidades de promoção social que decorriam da nomeação, neste caso, pelas consortes régias, para vários dos lugares de administração central deste domínio senhorial. Assim, e no caso em estudo, antes de chegarem a secretários e chanceleresmores das rainhas, pelo menos cinco dos indigitados ocuparam, previamente, outros cargos do governo da Casa das Rainhas. António de Basto Pereira foi, progressivamente, procurador da fazenda, conselheiro, ouvidor geral e ouvidor da fazenda das consortes régias ${ }^{40}$. O segundo Belchior do Rego de Andrade seguiu, de igual modo, este percurso, com a excepção de ouvidor geral das terras das soberanas $^{41}$. E tanto João Vaz de Carvalho, como Manuel de Almeida de Carvalho e Manuel Gomes de Carvalho foram, por ordem cronológica, membros do Conselho, exceptuando o último ${ }^{42}$.

\footnotetext{
${ }^{35}$ Para tudo isto, vejam-se as listas dos secretários e chanceleres-mores da Casa no nosso trabalho: Lourenço, Casa, vol. I, 553-581.

36 Ibídem, 116-125.

${ }^{37}$ Subtil, O Desembargo, 324; AN/TT, Chancelaria de D. Afonso VI, liv. 21, fl. 106.

38 AN/TT, Chancelaria de D. Pedro II, liv. 63, fls. 315v.e 316.

39 AN/TT, Casa das Rainhas, Chancelaria, liv. 2, fls. 315 v. e 316.

${ }^{40}$ AN/TT, Casa das Rainhas, Chancelaria, liv. 7, fls. 369-370.

41 AN/TT, Casa das Rainhas, liv. 118, fls. 47 v. e 58 e 59 v. AN/TT, Casa das Rainhas. Chancelaria, liv. 10, fls. 291v., 292, 384v. e 349.

${ }^{42} \mathrm{AN} / \mathrm{TT}$, Casa das Rainhas, Chancelarialiv. 6, fls. 114v. e 115.
} 
A nomeação para secretário e chanceler-mor da rainha ou do infantado constituía, pois, o corolário final para um grupo exíguo entre o conjunto dos magistrados que serviam, cada uma das consortes régias nos vários departamentos administrativos, em especial, para aqueles que eram conselheiros ou deputados no Conselho da Fazenda da Casa. Que a indigitação para tão prestigiante função era uma recompensa pelos serviços feitos nos outros sectores governativos desta estrutura senhorial, não parece deixar margem para equívocos, pois que os textos das respectivas nomeações aludem recorrentemente às "partes», "zelo», "qualidades», «inteireza», mas acima de tudo, a «muita confiança», que constituíam em rigor, os requisitos abonatórios para a escolha de um secretário/chanceler da Casa ${ }^{43}$. Ao contrário da carreira típica de promoção por antiguidade, este grupo restrito era escolhido pelas sucessivas rainhas, ficando o acesso ao lugar máximo do governo da Casa dependente da arbitrária e contingente vontade das soberanas. Acresce que vários dos indigitados, ao longo do período considerado, terminaram a sua carreira administrativa como secretários da Casa das Rainhas, tendo ainda José Vaz de Carvalho desempenhado as funções de Chanceler da Casa da Suplicação, Manuel de Almeida de Carvalho as de Conselheiro do Conselho Ultramarino e Manuel Gomes de Carvalho as de Chanceler-mor do Reino. Seguramente, que a experiência como secretários e chanceleres-mores da rainha D. Maria Ana de Áustria, lhes abriu as portas para estas prestigiantes nomeações. Note-se, ainda, que André Franco será escolhido para um dos lugares de deputado da Mesa da Consciência e Ordens em virtude dos serviços prestados nos cargos de desembargador dos Agravos da Casa da Suplicação e de secretário da Rainha ${ }^{44}$.

Por tudo aquilo que ficou enunciado, o cargo de secretário e chanceler-mor das Rainhas revestia-se de uma importância excepcional no quadro dos demais poderes administrativos da Casa. De facto, esta função era considerada pelos contemporâneos «como muito bom lugar, pois [...] despacha só com a Rainha e faz tudo o que quer» ${ }^{45}$. E que os secretários das rainhas exercitavam influências de natureza governativa e cortesã, parece ser bem ilustrado pela destituição de Pedro de Almeida do Amaral desse cargo por ser valido do Conde de Castelo-Melhor e eventual «traidor» aos desígnios de D. Maria Francisca Isabel de Sabóia ${ }^{46}$. Aliás, será, precisamente, o fiel servidor de D. Luísa de Gusmão e pertencente à facção de D. Pedro, Belchior do Rego de Andrade, que, após 1668, servirá de secretário e chanceler-mor da princesa de Nemours.

Embora nem sempre seja fácil captar as rivalidades socioprofissionais entre secretários ou entre membros das estruturas centrais da administração da Casa, decerto que existiu uma disputa constante no sentido de assegurar o monopólio do

43 AN/TT, Chancelaria de D. João IV, liv. 16, fl. 467.

${ }^{4}$ BNP, Gazeta de Lisboa (...),fl. 141.

${ }^{45} \mathrm{BNP}$, Monstruosidades do Tempo e da Fortuna (...), tomo I, p. 83.

${ }^{46}$ Sobre o poder dos secretários, no caso espanhol, veja-se Carlos Javier de Carlos Morales, "El Poder de los Secretarios Reales: Francisco de Eraso", en La corte de Felipe II, dir. José Martínez Millán (Madrid: Alianza Editorial, 1994), 107-148. 
favor das rainhas, que era, antes demais, garantido pela tutela do cargo de secretário e de chanceler-mor. A proximidade cortesã com a rainha- quer no despacho dos negócios da Casa, quer na gestão influente do patrocinato da soberana- pôde garantir, em várias circunstâncias e graças ao prestígio e poder decisório destes juristas, a colocação na Casa e nos vários conselhos da monarquia de gente do seu clã, em especial, de sua família ${ }^{47}$.

Para exemplificar, Pedro de Almeida do Amaral conseguiu, graças aos seus serviços à Casa, obter para o seu filho homónimo o cargo de corregedor do cível da cidade de Lisboa, a que um estratégico matrimónio com a filha de outro desembargador, António dos Santos de Oliveira, garantiria a posse de um lugar de desembargador extravagante do Porto, desta feita recolhendo os louros dos préstimos do sogro à Casa Real ${ }^{48}$. Não obstante, a "mancha de mecânica" do avô materno do segundo Pedro de Almeida, este será dispensado nas habilitações para cavaleiro da Ordem de Cristo, conquistando ainda um lugar de familiar do Santo Ofício $^{49}$.

Por seu turno, José Vaz de Carvalho consolidou o poder da sua família, que o doutor Gonçalo Vaz Pereira iniciara - de simples juiz de fora de Seia a conservador na Universidade de Coimbra e a familiar do Santo Ofício- que seu filho, Gonçalo José da Silveira Preto continuaria. Para além de indigitado, como veremos, para um dos lugares de deputado do Conselho da Fazenda da Casa da Rainha, este último, e em reconhecimento dos serviços de seu pai, viria a ser procurador da fazenda da repartição do Ultramar ${ }^{50}$.

De todos, o exemplo de maior sucesso no que diz respeito à colocação de membros da sua família ao serviço das consortes régias foi, sem dúvida, o de Belchior do Rego de Andrade. Descendendo de uma família de reconhecida fidelidade à Casa de Bragança, continuaram, quer pela mão do primeiro Belchior, distinto jurista e secretário de três das rainhas- desembargador da Casa de Bragança, Chanceler da Corte e da Junta do Infantado, no período em estudo, quer pelos serviços de seu irmão, António de Andrade Rego, desembargador da Relação do Porto, os Rego de Andrade serviram a Casa das Rainhas e, em geral, a monarquia. Os serviços dos pais e tios são, amiúde, relembrados pela sua descendência. E se Inácio do Rego de Andrade «apenas» viria a ser deputado, conselheiro e ouvidor geral das terras das rainhas, os seus filhos - o segundo Belchior e o segundo António do Rego de Andrade - ocupariam, respectivamente, os lugares de secretário e chanceler-mor e de conselheiro da mesa da fazenda da Casa de D. Maria Ana de Áustria ${ }^{51}$.

47 AN/TT, Chancelaria de D. Pedro II, liv. 28, fls. 186 e 186v.

48 AN/TT, Habilitações da Ordem de Cristo, letra P, maço 11, doc. 44. AN/TT, Habilitações do Santo Ofício, maço 12, no 293.

49 AN/TT,Chancelaria de D. João V, liv. 107, fl. 229.

50 AN/TT, Casa das Rainhas, liv. 118, fl. 42.

${ }^{51}$ Elogio fúnebre de Belchior do Rego de Andrade (...). 
Por tudo isto, é pertinente concluir que a influência cortesã de secretários e chanceleres-mores se exercitou, a um primeiro nível, na colocação de filhos, irmãos, sobrinhos, netos ao serviço da monarquia, reforçando, desta forma, o protagonismo clientelar de certas famílias de juristas. Verdadeiras «linhagens» de juristas que, como vimos, dominavam os principais conselhos da Casa Real e das Casas da Família Real, irradiando, muitas das vezes, o seu poder e influência clientelar até às instituições administrativas periféricas.

Por outro lado, o engrandecimento patrimonial e económico destas famílias de juristas pôde consolidar-se com o notável desempenho de cargos nas estruturas administrativas da monarquia. As estratégias, matrimoniais, a instituição de morgados, de capelas, ou o simples usufruto de rendas, juros, emolumentos, foram algumas das formas de reforço do prestígio numa «sociedade de corte». Mas o reconhecimento público da «limpeza de sangue» era imperioso. A posse de um hábito de uma Ordem Militar, em especial a de Cristo, era crucial para todos. Sobretudo para os afamados de «sangue cristão-novo» ou de sangue «menos nobre». A nobilitação, a entrada plena na «fidalguia» era o objectivo último (e talvez o primeiro) desta elite de magistrados, para a qual a formação académica fora o primeiro passo.

A fixação modelar da imagem do magistrado e da sua linhagem- tal como qualquer outro membro da nobreza de «sangue»-fez-se pelos processos escritos tradicionais que visavam preservar os actos e a memória de homens notáveis pela honra, pelo sangue ou pelo serviço exemplar à monarquia: os elogios e as orações fúnebres. De sublinhar que o elogio fúnebre do segundo Belchior do Rego de Andrade, aliás, como já referimos, foi proferido pelo Marquês de Valença, evidenciando que não repugnava à nobreza de «espada» elogiar a nobreza de «letras», sobretudo quando se tratava de um dos seus principais arautos ${ }^{52}$.

Aliás, o estudo que se seguirá dos deputados e conselheiros da Casa das Rainhas tentará averiguar, entre outros aspectos, até que ponto a preeminência social da magistratura lutou contra o poder e prestígio da nobreza de espada, ou, se pelo contrário, a primeira foi prisioneira do imaginário político da segunda, lutando sim pela conquista da «honra», do êxito social, da reputação e fama de «nobre». O alcançar pelas «linhagens» de juristas de um lugar na memória social foi, por vezes, espinhosa. Mas não raro foi conseguida.

Estudada que já foi por nós a jurisdição e competências de ambos os tribunais, importa seguir, um pouco mais de perto, o percurso dos conselheiros de ambas as instituições.

Do corpo de oficiais do Conselho e da Junta podemos distinguir três grupos distintos: um primeiro núcleo constituído pelos homens de justiça, procuradores, conselheiros e ouvidores da rainha: ouvidor da Fazenda e ouvidor Geral das terras da

${ }^{52}$ Lourenço, Casa, vol. II, 788. 
consorte régia; um segundo, que incorporava o oficialato da fazenda: escrivães, tesoureiros da fazenda, do tesouro e dos contos; e por fim, agentes e porteiros do Conselho.

Muito embora o seriar deste corpo de oficiais fosse feito, em geral, pela rainha, que indigitava todos os membros do seu Conselho, imperavam regras e critérios de selecção que importa enunciar. Entrava-se, por regra, ao serviço dos cargos superiores do Conselho da Rainha desempenhando a função de procurador da fazenda, ascendendo, em seguida, desde $3^{\circ}$ ao $1^{\circ}$ lugar de deputado- aguardando por vezes alguns meses ou mesmos anos como conselheiro supranumerário - até aos cargos de ouvidores gerais das terras e de ouvidores da Fazenda.

Analisemos, pois, quais as funções, prerrogativas e perfil social dos ministros letrados do Conselho da Fazenda Rainha, entre 1642 e 1754. Por comparação iremos fazendo referência a similar enquadramento da Junta da Fazenda do Infantado.

No que diz respeito à proveniência social dos letrados em análise, podemos considerar que um número muito significativo destes ministros descendia de famílias ligadas à Casa e Corte das rainhas, em particular ao serviço da Câmara e, sobretudo, a linhagens de letrados e servidores da Casa Real. Encontravam-se, nesta circunstância, Gaspar de Abreu de Freitas, filho de Luís de Abreu de Freitas, cavaleiro da Ordem de Cristo e escrivão da câmara do rei e da rainha, João da Silva Machado Morais, fidalgo da Casa Real, porteiro da câmara da Rainha. E, também, os casos de Inácio do Rego de Andrade, bem como os descendentes e homónimo, António do Rego de Andrade. Por sua vez, Gonçalo José da Silveira Preto era filho do desembargador Vaz de Carvalho, conselheiro e secretário das rainhas e Manuel Lopes de Lavre era filho de um velho servidor da Casa. Aliás, foram estas três famílias - Os Rego de Andrade, os Vaz de Carvalho, Preto e Giraldes - as que colocaram um maior número de familiares letrados ao serviço das estruturas de administração central e senhorial da Casa ${ }^{53}$. Por outro lado, João de Sousa de Cardenas era filho de D. Pedro de Cardenas Sottomayor, desembargador da Casa da Suplicação, António de Basto Pereira era, como já vimos, filho do doutor Luís Gomes de Basto, fidalgo da Casa Real, Rodrigo de Oliveira Zagalo era neto do desembargador Agostinho de Oliveira Rebelo, vereador da Câmara de Lisboa, Fernão Giraldes era neto homónimo, o licenciado Fernão Afonso Giraldes e Diogo Lobo Pereira era neto do desembargador com o mesmo nome. Ou seja, filhos ou descendentes de juristas e letrados que serviam por tradição a Casa Real ${ }^{54}$. Por sua vez, vários dos ministros da Casa descendiam de fidalgos da Casa Real, de cavaleiros da Ordem de Cristo e de familiares do Santo Ofício. Citem-se, entre outros, os exemplos de Gonçalo Meireles Freire, fidalgo da Casa Real, de Manuel Gameiro Barros, filho de cavaleiro fidalgo da Casa Real, de José da Cunha Brochado e de Gaspar de Almeida de Andrade ${ }^{55}$.

\footnotetext{
53 Ibídem, vol. II, 789.

54 Ibídem, vol. II, 789.

55 Ibídem, vol. II, 789-790.
} 
Mas quando não se refere a fidalguia da Casa Real, reclama-se quase sempre a «nobreza» como estrato social de origem do corpo de letrados que serviram as rainhas, no período em estudo. Avós, pais e familiares que «viviam por sua fazenda», à «lei da nobreza», «com negras, negros e cavalos»; e que eram «dos principais das vilas», são com frequência as referências sociais apontadas. Manuel Manso da Fonseca, Gaspar de Almeida de Andrade, Duarte Salter de Mendonça e João Marques Bacalhau, são alguns dos que se posicionaram neste escalão social. Outros, como Domingos Nogueira de Araújo, José da Cunha Brochado, filho de militar que servira no Alentejo e na Índia, recebendo como recompensa a ordem do hábito de Santiago, no segundo exemplo, filho do tenente-governador do Castelo de S. Jorge e familiar do Santo Ofício e, por último, Manuel Mariz Sarmento que fora mestre de campo de um dos terços da infantaria que servira nas Guerras da Restauração, irmão do alcaide-mor de Bragança e comendador da Ordem de Cristo ${ }^{56}$.

Em resumo, gente ligada à defesa do território durante as Guerras da Restauração, que muitas das vezes se nobilitara ao serviço da dinastia brigantina. De igual modo, filhos de notáveis locais das terras das rainhas serviram no Conselho, como atestam Manuel Gameiro de Barros, filho do juiz dos órfãos da vila da Chamusca e Ulme, e Luís Pimentel da Costa, sobrinho do cónego da Sé de Faro.

Descendentes, portanto, de nobres titulados ao serviço da Casa Real, de uma fidalguia de serviço, sendo apenas de registar um conselheiro titulado, a saber, D. Tomás de Almeida, filho dos condes de Avintes, casa que se distinguiu no servir da Rainha.

Contudo, pelo menos, seis dos mais notáveis conselheiros e deputados tinham origens humildes, tais como Francisco Ferreira Baião, filho de boticário, Jerónimo Vaz Vieira, filho de foleiro, Inácio da Costa Quintela, cujo pai fora sirgueiro de chapéus e mercador de grosso trato, Manuel Rodrigues Leitão, filho de sapateiro e Alexandre Ferreira, cujos avós e pais foram mercadores de livros ${ }^{57}$. O que significa que a carreira universitária e a formação letrada permitiam uma mobilidade social notável, mesmo para um filho de alguém com profissão «mecânica», que poderia ascender até ao cargo de conselheiro, deputado e mesmo de ouvidor da Fazenda do Conselho da Rainha, à imagem do que sucedeu com Jerónimo Vaz Vieira. Diga-se em boa verdade, que vários dos escrivães dos Contos e da Tesouraria da Casa das Rainhas foram habilitados como familiares do Santo Ofício, citando apenas o caso de Domingos Miranda, natural de Montelavar, Sintra, morador em Lisboa, escrivão dos gastos secretos de Sua Majestade, contador da fazenda da Casa de Bragança e do Infantado e da Casa da Índia e que, sendo legítimo e inteiro cristão-velho «sem raça de nação infecta», é habilitado em 26 de Abril de $1700^{58}$.

56 AN/TT, Habilitaçoes do Santo Ofício, Francisco, maço, 14, diligência no 428; ibídem, Jerónimo, maço 2, no 55; ibídem, Inácio, maço 31, diligência no 52; ibídem, Manuel, maço 29, diligência 664; AN/TT, Habilitações da Ordem de Cristo, letra A, maço 2, no 20.

${ }^{57}$ Ibídem, AN/TT, Domingos, Maço n $2, \mathrm{n}^{\circ} 39$.

58 AN/TT, Habilitações da Ordem de Cristo, letra M, maço no 43, doc. $\mathrm{n}^{\circ} 46$. 
Do ponto de vista da proveniência geográfica de procuradores, conselheiros e ouvidores, a maior parte nasceu em Lisboa e seu termo, o que sublinha, uma vez mais, o recrutamento maioritário de ministros nas elites letradas da Corte e Casa Real. Porém, de muitas outras cidades, vilas e terras vieram aqueles que desempenhariam as tão importantes funções de procuradores e conselheiros das consortes régias.

Do total dos 36 ministros da Casa das Rainhas- exceptuando os secretários que, entre 1642 e 1754, desempenharam funções no Conselho das Rainhas, pelo menos doze, foram agraciados com a posse de um hábito da Ordem de Cristo, sendo apenas um detentor de um hábito da Ordem, de Santiago. De um modo geral, receberam essas insígnias antes de ocuparem funções no Conselho das Rainhas, embora, num ou noutro caso, tenham obtido essa distinção honorífica após o desempenho de importantes cargos na administração central e nesta Casa da Família Real.

Como sublinhámos anteriormente, ser aprovado na habilitação de genere para a obtenção de um hábito da Ordem de Cristo, constituía prova pública da limpeza de sangue, por todos almejada, mas, sobretudo, desejada por aqueles de proveniência social menos afortunada, que viam neste título de confirmação social da sua «honra», da sua «nobreza». É assim que, não obstante o pai de Manuel Lopes de Lavre ser infamado de «ter raça de nação», sendo, por outro lado, seu avô marchante e mercador de gado, a família de Lavre consegue alcançar as honoríficas distinções da Ordem de Cristo e de familiares do Santo Ofício ${ }^{59}$. De igual modo, e apesar de constar que o pai e avô materno de Manuel Rodrigues de Leitão haviam sido sapateiros, o beneficiário é dispensado destes defeitos na habilitação de genere para a obtenção do hábito de Cristo $^{60}$; ou de Domingos Nogueira de Araújo, que na habilitação de genere da Ordem de Santiago foi dispensado no defeito da falta de nobreza do seu avô materno- sapateiro e surrador-, e do seu avô paterno que fora trabalhador, em virtude dos serviços de seu pai como militar nas Guerras da Restauração ${ }^{61}$.

Para além disso, pelo menos, treze dos ministros do Conselho foram familiares do Santo Ofício. Na maioria dos casos, com uma ou outra excepção, receberam essa distinção antes de exercerem importantes funções na administração superior do Reino. Para homens como Francisco Ferreira Baião, Jerónimo Vaz Vieira, Inácio da Costa Quintela, Manuel Rodrigues Leitão, Manuel Lopes de Lavre, João Marques Bacalhau, Domingos Nogueira Leitão, com raízes humildes e, sobre ao quais recaía, por vezes, a suspeita de «mecânica» ou de «cristã-novice», ser familiar do Santo Ofício constituía mais uma prova de honorabilidade e de «nobreza» adquirida pelos serviços prestados à Casa Real, a que se juntavam a outras honras e habilitações de genere. Alegando-se, com frequência, que pais, avós ou outros parentes, haviam

${ }^{59}$ Ibídem, letra M, maço n $\mathrm{n}^{\text {44, doc. }} \mathrm{n}^{\circ} 70$.

${ }^{60} \mathrm{AN} / \mathrm{TT}$, Habilitações da Ordem de Santiago, Letra D, maço 2, no 39.

${ }^{61}$ Lourenço, A Casa e o Estado, 121. 
casado com filhas de familiares, reforçando-se, desta forma, a endogamia familiar em torno de uma instituição. O mesmo sucedia com a Casa do Infantado, onde encontramos a habilitação de familiar do Santo Ofício de Bento da Fonseca, em 1773, quando tinha desempenhado funções de desembargador supranumerário da Junta e de desembargador dos Agravos da Casa da Suplicação ${ }^{62}$. Ou de Inácio Pereira de Sousa, doutor colegial de S. Pedro, desembargador da Junta, desembargador da Casa de Bragança, alcançando mais tarde o lugar de deputado da Mesa da Consciência e Ordens, tendo-se habilitado a familiar, com sucesso, em 23 de Dezembro de $1675^{63}$. Mas para muitos dos nomes sonantes da Junta da Fazenda não encontramos habilitação do Santo Ofício como, por exemplo, António Cavide, António de Sousa Tavares, João de Roxas, todos da Secretaria da Junta do Infantado.

Um número avultado de ministros do Conselho das Rainhas era constituído por bacharéis em Direito Canónico ou em leis (c.12), sendo os demais licenciados (7); um número limitado tinha alcançado o grau de doutor (5) ou desempenhava funções de lente da Universidade de Coimbra ou dos colégios reais (2). Por outro lado, sete dos ministros foram colegiais dos principais colégios da Universidade de Coimbra, respectivamente, cinco de S. Paulo e dois de S. Pedro. Estamos, portanto, uma vez mais, perante um corpo de ministros de prestigiada formação universitária. Alguns desempenharam mesmo as funções de maior destaque nessas instituições como doutores, lentes ou reitores. Adiante-se, ainda, que as informações da Universidade de Coimbra a propósito da maior parte destes ministros caracterizamnos como «muito bons» e de «bom procedimento», o que permite concluir pela excelentel formação letrada deste corpo de oficiais.

Por outro lado, e nos casos (23) para os quais foi possível encontrar a habilitação para a leitura de bacharel, e respectiva informação final do Desembargo do Paço, todos foram aprovados tendo tido a maior parte «bem» ou «muito bem» por todos, o que consistia na classificação aprovada para transitar na leitura, com vista a ocupar um lugar de letras da administração central. Tal como foi observado para os secretários da Casa, voltamos a estar perante um conjunto de oficiais que foram na sua totalidade desembargadores, o que os caracteriza como um corpo específico, quer em prerrogativas, quer nas carcterísticas de progressão na carreira. O que significa, como já foi sublinhado, que estamos, perante um oficialato de elite, que desempenhava os principais cargos da administração superior e que, como tal, detinha uma substancial fatia do poder político.

No conjunto dos ministros do Conselho das Rainhas podemos considerar que cerca de metade (17) alcançou o cargo de desembargador pelo percurso normal de juiz de fora ou de corregedor de uma magistratura territorial até ser nomeado para desembargador da Relação do Porto transitando, em seguida, para o Desembargo do Paço. Por outro lado, a outra metade parece ter sido nomeada, de imediato, para o

\footnotetext{
${ }^{62}$ Ibídem, 120.

${ }^{63}$ Lourenço, A Casa, vol. II, 790-800; Lourenço, Casa, vol. II, 790-800.
} 
cargo de desembargador extravagante da Relação do Porto, sem que tivessem ocupado qualquer lugar da magistratura territorial ${ }^{64}$.

Com efeito, a maioria dos ministros do Conselho desempenhou funções como desembargadores na Relação do Porto (17) e/ou na Casa da Suplicação (22) antes de terem ocupado os lugares de magistratura do Conselho da Rainha. Por outro lado, alguns dos procuradores da fazenda da Casa (3) já haviam sido procuradores da Coroa, bem como, pelo menos quatro dos conselheiros das rainhas haviam desempenhado idênticas funções na administração central. Todavia, se esse desempenho não constituía condição sine qua non para o acesso à magistratura da Casa, nos casos em que tal sucedeu verificou-se que a anterior passagem por estes departamentos os habilitava a uma avaliação experiente e conhecedora das matérias de despacho e consulta das soberanas. Todavia, de um modo geral, após o desempenho das magistraturas no Conselho das Rainhas, esperava aos seus juristas a progressão a lugares de maior distinção, tais como o de conselheiro da fazenda (5), de conselheiro ultramarino (1), de procurador da Coroa (1), de deputado da Mesa da Consciência e Ordens, de desembargador do Paço (3), de chanceler das Ordens Militares (1), de conselheiro do rei (8) ou mesmo secretário de Estado (1) ${ }^{65}$.

O facto da contagem de serviço e da categoria adquiridas nos lugares de provimento da Casa das Rainhas - tal, como sucedia, aliás, com a de Bragança e do Infantado- ser acumulável, podendo o candidato pedir equivalência para o provimento em lugares da Coroa, tornava, por certo, as magistraturas das Casas da Família Real apetecíveis, em especial, como trampolim para lugares de maior importância jurídica e honorífica. Aliás, entre o desempenho de tarefas no Conselho das Rainhas e a indigitação para um cargo da magistratura da Coroa, distou em média quatro a cinco anos, o que confirma a celeridade da progressão nos mais elevados postos da monarquia para este corpo de ministros.

Contudo, o exercício das tarefas de ministro do Conselho das Rainhas e da Casa do Infantado revestia-se de uma inquestionável primazia. Isso mesmo é revelado pelo facto de alguns dos conselheiros da fazenda terem morrido ao serviço da Casa, em especial os que chegaram ao topo da hierarquia administrativa como secretários; ou para aqueles que, apesar de desempenharem já funções de conselheiros da fazenda e/ou de conselheiros como, por exemplo, João Marques Bacalhau, Fernão Afonso Giraldes, António de Andrade de Rego, Inácio da Costa Quintela ou de procurador da casa, como foi o caso de Francisco Mendes Galvão, virem a ser nomeados para o serviço das rainhas. Para esta circunstância contribuiu, sem dúvida, o facto de os ministros da Casa das Rainhas possuírem os mesmos privilégios que os do Desembargo do Paço, pelo que pertencer à elite de juristas deste Conselho representava um privilégio raro e uma honra prestigiante. Por seu turno, vários dos desembargadores do Paço, mesmo para além do período em estudo,

\footnotetext{
${ }^{64}$ Subtil, O Desembargo, 271.

${ }^{65}$ Lourenço, Casa, vol. II, 796.
} 
acumularam esse cargo como o de conselheiro e juízes da Casa das Rainhas e/ ou das demais Casas da Família Real ${ }^{66}$.

O que aponta, em última instância, para a criação a partir da Resturação de conselhos adstritos às Casas da Família Real, idênticos em privilégios e prerrogativas ao Desembargo do Paço, colocando, por isso, ao mesmo nível poderes e honras, os seus oficiais. O que, longe de criar uma cadeia hierárquica de comando centralizada no Desembargo do Paço, assegurava, apenas, a centralidade das decisões régias, através da circulação funcional desses ministros pelas várias instituições administrativas da Coroa, tuteladas pelos diversos membros da Família Real. Incapacidade de adequar a especificidade das regras dos espaços político administrativos das sociedades modernas e, em particular, ao de a Portugal, aos dispositivos institucionais conhecidos e disponíveis para a época? Pensamos bem que sim. E que esta deve ter sido a via encontrada para implementar e controlar algumas reformas de Estado colmatando, sempre que possível, os obstáculos colocados pelas diferentes autonomias jurisdicionais, que eram impostas pelo modelo polissinodal de governação. Sem dúvida, que a imposição em todos esses tribunais de normas jurídicas semelhantes, em que as consultas e muitas das decisões eram tomadas pelo mesmo corpo de juristas, facilitou, indiscutivelmente, a proliferação do direito escrito e erudito de proveniência régia. Mas as jurisdições senhoriais de cada uma dessas Casas mantiveram-se. E foi, quase sempe em última análise, a defesa da mesma linhagem, da mesma família, na circunstância, a Casa de Bragança.

Do ponto de vista dos beneficiários, neste caso, os juristas e conselheiros dos diversos conselhos, esta estrutura polissinidal era largamente vantajosa. Proporcionava a um grupo muito restrito, a elite de juristas e de altos oficiais, a posse de cargos, de poderes, de honras e de emolumentos que se podiam acumular e sobrepor, tornando-os num dos corpos mais destacados de uma sociedade de privilégios e de privilegiados.

Para além disso, a própria Casa proporcionava a progressão no interior das estruturas administrativas e, no caso em análise, na orgânica interna do Conselho. De facto, dezassete juristas que iniciaram a sua carreira no Conselho como procuradores da fazenda, apenas um permaneceu nessa categoria, tendo doze chegado a conselheiros e dez a ouvidores gerais. Por sua vez, seis conseguiram alcançar o prestigiante cargo de ouvidor da fazenda e destes, apenas um, o lugar de secretário da rainha. Os múltiplos serviços à Casa foram determinantes para esta progressão já que, do ponto de vista das suas habilitações literárias, tanto os bacharéis como os licenciados e os lentes universitários ocuparam os lugares com maior poder decisório e influência jurídica e política no interior do Conselho, isto é, os de ouvidores da fazenda. Por outro lado, os conselheiros seguiram percursos diversos até atingirem-

${ }^{66}$ Ibídem, vol. II, 797. 
quando o conseguiram - o topo da pirâmide administrativa do Conselho das Rainhas ${ }^{67}$.

No caso lapidar de Manuel Manso da Fonseca, a sua carreira de jurista terá terminado com o desempenho desse cargo, enquanto que, para a maioria, o exercício dessa destacada magistratura precedeu a tutela de idênticos ou superiores cargos de magistratura do Reino. Em todo o caso, a experiência granjeada no despacho do Conselho das Rainhas habilitava, preferencialmente, esta plêiade de juristas, para o desempenho das mais altas magistraturas da Coroa, bem como de outras Casas da Família Real, onde alguns haviam exercido funções similares.

Para além de todos os privilégios e prerrogativas inerentes ao cargo de desembargador, de entre os quais a própria nobilitação, pertencer ao grupo restrito dos juristas do Conselho das Rainhas proporcionava honras, títulos, mrcês e poderes que se alargavam, na maioria das vezes, aos respectivos clãs familiares. Sem dúvida, que os méritos garantiram promoções e prerrogativas, mas sólidas e influentes relações familiares e estratégicos casamentos consolidaram o poder de certas linhagens de juristas que, de pais para filhos e netos, transmitiram e aliçercaram a legitimidade social desta fidalguia letrada.

Muito embora nos vários cargos do Conselho se sucedessem nomes diferentes, mas, não raro, parentes próximos ou mais distantes foram recrutados para o serviço das soberanas. Por outro lado, muitos dos letrados eram filhos de desembargadores ou de juristas que haviam ocupado lugares de destaque nas vida jurídica do Reino. Neste sentido, Jerónimo Vaz Vieira era sobrinho do desembargador com o mesmo nome, legando depois a seu filho homónimo um património significativo em padrões de juro e bens de morgado ${ }^{68}$. Por sua vez, Manuel Gameiro Barros era sobrinho de Francisco Lopes de Barrros, Chanceler do rei e da Casa da Suplicação e membro de uma das famílias mais notáveis da Chamusca ${ }^{69}$. Certo é que um bom casamento facilitava muito. E não será por acaso que o supracitado jurista alcançou o lugar de desembargador extravagante da Relação do Porto em virtude dos serviços de seu tio por afinidade, casado que estava com D. Antónia de Barros, essa sim, sobrinha de sangue. De igual modo, Manuel Manso da Fonseca era casado com D. Antónia do Rego, filha de Crispim Rego, médico e familiar do Santo Ofício ${ }^{70}$ e Gaspar de Almeida de Andrade casara com D. Maria Joana de Castro, filha do desembargador Fernão Tudela Castilho ${ }^{71}$.

${ }^{67}$ AN/TT, Habilitações do Santo Ofício, Jerónimo, maço 2, diligência no 55.

68 AN/TT, Habilitações do Santo Ofício, Francisco, maço no 11 , diligência, no 317.

${ }^{69} \mathrm{AN} / \mathrm{TT}$ T, Habilitações do Santo Ofício, Manuel, maço 20, diligência n ${ }^{\circ}$ 502, AN/TT, Francisco, maço 11 , diligência no 315 .

70 AN/TT, Habilitações do Santo Ofício, Manuel, maço 20, diligência no 502. AN/TT, Gaspar,maço 6, diligência $\mathrm{n}^{\circ} 48$.

${ }^{71}$ AN/TT, Habilitações do Santo Ofício, Gaspar, maço 6, diligência, no 48. 
Porém, do cômputo geral das linhagens de juristas que serviram o Conselho das Rainhas, três sobressaem como tendo colocado o maior número de parentes neste departamento da Casa. Os Lopes de Lavre, pai e filho, ambos familiares do Santo Ofício, serviram anos a fio a instituição . Por sua vez, a família de José Vaz de Carvalho, cujo filho, Gonçalo Vaz de Preto foi conselheiro, era aparentada com a de Fernão Afonso Giraldes, seu homónimo. Mas, entre todos, sobressai pelo número (6) e pela categoria dos cargos desempenhados a família Rego de Andrade, ligada à Casa dos duques de Bragança, que, ao longo de anos, continuará dedicada ao serviço da dinastia brigantina. Para além do velho Belchior do Rego e Andrade e seu irmão, António de Andrade de Rego, tanto o sobrinho do primeiro como o filho do segundo, continuaram servindo a Casa. E na linha de descendência directa, outros dois «Antónios» do Rego de Andrade ocuparam as funções de conselheiro das rainahas.

Prestígio de uma nobreza letrada, socialmente útil e recompensada e, como tal, juridicamente reconhecida, que luta denodadamente pela conquista de um lugar privilegiado no quadro das categorias sociais de Antigo Regime. Prestígio que era visível não só através dos sinais exteriores de «honra social», tais como a posse das prerrogativas de desembargador, das insígnias de uma Ordem militar ou do exercício das funções de familiar ou deputado do Santo Ofício; como, para além disso, pelas honras específicas atribuídas aos conselheiros da Casa das Rainhas.

A disposição hierárquica dos magistrados nas sessões de despacho do Conselho, bem como a participação honorífica em todas as cerimónias ligadas à vida deste tribunal, asseguravam posições de preeminência indiscutível que, segundo códigos, regras e precedências representavam poderes e prerrogativas de diversificada natureza. Mas no exterior, em cerimónias religiosas, o Conselho da Rainhas estava representado pelo seu corpo de juristas. É assim que para vários anos se registam os gastos com a cera despendida pelos ministros e oficiais do Conselho que acompanharam, em anos seguidos, a procissão do Corpo de Deus. Para já não referirmos emolumentos, ordenados, propinas, mantimentos ou ajudas de custo para deslocações, para cura de doenças, funerais dos próprios ou de familiares, ou para roupas de luto, de uso obrigatório, pelos membros do Conselho, na circunstância da morte de um dos membros da Família Real ${ }^{72}$.

É nossa convicção que com todos os trâmites descritos, as Casas da Família Real abriram as portas à promoção social, mesmo para aqueles sob os quais recaía, suspeitas de «cristã-novice», mas que os serviços fiéis de sucessivas gerações à Casa Real Portuguesa, libertaram-nos honradamente do «pesadelo» do passado, do presente e do futuro.

${ }^{72}$ AN/TT, Casa das Rainhas, n 66, fl. 133v. 
Recibido: 30 de julio de 2017 Aprobado: 12 de octubre de 2017 